\title{
Amantadine Sulfate
}

National Cancer Institute

\section{Source}

National Cancer Institute. Amantadine Sulfate. NCI Thesaurus. Code C90781.

The sulfate salt of amantadine, a synthetic tricyclic amine with antiviral, antiparkinsonian, and antihyperalgesic activities. Amantadine appears to exert its antiviral effect against the influenza A virus by interfering with the function of the transmembrane domain of the viral M2 protein, thereby preventing the release of infectious viral nucleic acids into host cells; furthermore, this agent prevents virus assembly during virus replication. Amantadine exerts its antiparkinsonian effects by stimulating the release of dopamine from striatal dopaminergic nerve terminals and inhibiting its pre-synaptic reuptake. This agent may also exert some anticholinergic effect through inhibition of $\mathrm{N}$-methyl-Daspartic acid (NMDA) receptor-mediated stimulation of acetylcholine, resulting in antihyperalgesia. 